\title{
Reclaiming the Ontological Over the Epistemological: A Case Study Into a New Zealand Primary School Disclosing an Embodied Culture of Teacher Inquiry \\ New Zealand Journal of Teachers' Work, Volume 13, Issue 1, 61-78, 2016
}

\author{
ANDREW BILLS \\ Flinders University \\ BEV ROGERS \\ Flinders University \\ DAVID GILES \\ Flinders University
}

\begin{abstract}
This article presents case study research into a New Zealand primary school enacting a very sophisticated whole school inquiry approach to enhance teacher classroom professionalism and practice. A culture of inquiry manifests as an ontological 'way of being' in this school community, in the daily professional interactions between the teachers and leaders. This 'way of being' is evident in the way teachers and leaders work together in espousing professional expertise, trust, care and support to enable teacher inquiry for improved classroom practice to flourish. In this article we present evidence in relation to three questions: (1) What does inquiry look like within this school community? (2) How was collaboration and support implicated in teacher inquiry? (3) How was teacher and leader engagement in inquiry related to meaningful shifts in teachers' practice and learning? The research contributes to new understandings about the ontological nature of teacher inquiry by uncovering important links between school culture, teacher and leader inquiry, and embodied professional learning and practice.
\end{abstract}

\section{INTRODUCTION}

The purpose of this article is to reveal how teacher inquiry manifests in the professional learning experiences of the leaders and teachers in a New Zealand primary school which we have renamed Intrepid Primary School (IPS). We seek to reveal how IPS's dialogic teacher and leader learning community builds richer understandings of teacher inquiry within the school's professional learning and teaching practices. As lecturers in educational leadership, we argue that the focus for pedagogy can only be supported by teachers "who are themselves trusted and respected partners" (Hart, Dixon, Drummond, \& Mclntyre, 2004, p.266) in the education project and are enabled by leadership through contextually supportive school structures to have the dedicated space, time and support in place to regularly inquire into and reflect upon their own teaching practices. 
To this end, our research used conversational interviews conducted in October 2014 with the principal, leaders and teachers of IPS to understand and analyse the development and embedding of what IPS have called 'teacher capability matrices' (TCM) and teacher 'triples' that together provoke teacher inquiry and reflection for the improvement of every teacher's pedagogy. The matrices are enacted through a triples process where two people (a syndicate or team leader and an 'in school' expert) observe a teacher in an agreed area of development and provide questions and feedback and revisit previous goals. Part of the responsibility for their own and each other's learning is finding out how each teacher is working towards their goals and asking whether they need help to do this. Once teachers reach the 'Expert' level, they become a 'Tripler'.

As an alternative to the use of 'standards' in a performance management context (the approach evident in Australia's policy context), the research seeks to understand how teacher and leader generated contextualised statements of teacher capability-TCM-operate as a framework to promote teacher inquiry. In essence, we explore the impact of the triples process, in promoting teacher inquiry and in holding teachers accountable with collegial support for integrating what they have learned through inquiry-based professional development into their classroom practice.

\section{THE PROFESSIONAL INQUIRY CHALLENGE}

New Zealand and Australian schools are situated within a dominant public policy regime that is increasingly demanding compliance and standardisation. This is occurring at a time when the achievement of success for all students demands a capacity at the school level to design and deliver an approach that personalises the learning experience for students and embeds it as "an ongoing process of professional learning for teachers" (Caldwell, 2014, p. 4).

Within a neoliberal public policy regime (Connell, 2013), leaders are grappling with a standards-based context manifesting in a policy suite of mandated policies. In Australia standards are positioned for teachers within an Australian Teacher Performance and Development Framework, reinforcing the use of standards as 'recipes' for practice with decontextualised prescriptions (Rogers, 2015) for these practices. Yinger and Hendricks-Lee (2000) suggest that standards can support inquiry-based dialogue about teaching and learning, providing a platform for "reflection, discourse, and improvement among novices and experienced practitioners" (p. 104).

New Zealand's version of 'Standards' was announced in October 2009 and involves schools making and reporting judgements about the reading, writing and mathematics achievement of children up to Year 8 (the end of primary school). These judgements are made against a four-point scale ('above', 'at', 'below', or 'well below' the standard) and take place after one, two or three years at school in the junior school and then at the end of each year level in Years 4-8.

Four years after the introduction of the National Standards, Thrupp and White (2013), in their extensive and recent Research, Analysis and Insight into National Standards (RAINS) research project, find that "an official fixation with the data generated through the Standards is becoming abundantly clear" 
generating a "target-setting culture" (p. 1). The public release of data for each school on the 'Education Counts' website of the Ministry of Education is becoming increasingly sophisticated by being broken into year levels to facilitate between school comparisons. Thrupp and White (2013, p. 1) argue that there is a damaging cultural impact through "a compulsion developing within schools towards more data related to student achievement in literacy and numeracy in order to shore up teacher judgements against the Standards and fend off claims of underperformance". This compulsion is not directly in response to external pressures on schools from the Ministry and Education Review Office (ERO) but in relation to subtle policy effects which appear in "changing professional identities as principals, teachers and support staff in schools" (Thrupp \& White, 2013 , p. 1). How one considers oneself to be a 'good' principal or a 'good' teacher is at stake and is now implied by data comparisons that cast the teacher as technician. The

National Standards policy is creating the conditions within which teachers will 'do it to themselves'...there will only be a shift...away from the damaging excesses currently emerging when a different way to be a 'good' New Zealand teacher becomes sanctioned by policy. (p. 2)

In relation to New Zealand, we claim the enactment of curricular standards with their preoccupation with target setting for student learning, may significantly impact the professional learning space for teacher training and schooling. We are concerned that the current focus on professional development within the standards era, heralding the design and use of more sophisticated technologies of teacher control which can promote performativity cultures, can damage teacher inquiry culture, harm teacher efficacy and as a consequence, detrimentally impact the student learning experience (Ball, 2003).

A particular challenge to this discourse within the focus of teacher standards geared to ensure teacher quality comes from critical and humanistic concerns for professional development practices to foster growth in teachers' learning and their holistic formation as a person (Crooks, 2002; Freire, 2003; Shapiro, 2005). This shift in thinking gives greater attention and priority to the teacher learning process alongside former concerns for teacher quality (Absolum, 2007; Black \& William, 1998; Clarke, Timperley, \& Hattie, 2001; Harlen, 2007). There are examples of initial teacher education programmes and schools working with teachers to reshape professional development towards a greater concern for the importance of enabling inquiry-based professional development cultures to flourish (Elmore, 2002; Little, 2012; Sachs, 2001) by building on dialogic interactions which impact teacher ways of being. For us, the professional 'being' of the teachers and leaders represents an 'ontological turn' that predicates the success of the culture of inquiry approach at IPS. What we have noticed is that the epistemology offered through the various professional development and inquiry structures and processes in place at IPS was in the service of ontology (rather than the other way round) and we think this 'turn' is a highly significant phenomenon that we will consider more extensively in the discussion section.

Being responsive to learning needs requires understanding teacher standards in a particular context, which requires considerable knowledge about 
the immediate pedagogic situation to which they are applied (Yinger \& Hendricks-Lee, 2000). This points to a priority on relational sensibilities within educational practice that are sensitive to local context (Giles, 2014).

\section{THE RESEARCH STUDY}

\section{Participants}

The research was undertaken at the request of the principal following a whole of school negotiation process in late 2014. There were 25 participants in the study including the principal, the leadership team and the teachers, all at various stages of their careers. The IPS staff were individually interviewed for between 45 minutes and an hour. All of the IPS staff interviewed had experienced an ongoing and culturally embedded collegial inquiry approach comprising professional feedback from supportive teacher colleagues about regularly observed aspects of their teaching practices. These regular observations and feedback in tandem with the TCMs provoke the observed teacher in a professional inquiry of self to better understand how to develop and embody new capabilities to improve teaching practice.

\section{Originality}

The research has originality since we represent the stories and experiences of practicing leaders and teachers in relation to personal inquirybased professional development in the context of the school-developed teacher capability framework and the triples process conceived through teacher and leader collaborative inquiry which informs the ongoing formation of teachers and leaders.

\section{Methodology}

This case study research uses hermeneutic phenomenology methodology (van Manen, 1997, 1990) where lived experiences are told as descriptively as possible and insights are hermeneutically drawn from a thematic reading across the interview transcripts. The data within and across the individual cases was coded and hermeneutically analysed for emergent and powerful themes, which underpin how the TCMs enable dialogue with and between teachers and exploring how this occurs. Each teacher and leader in the school was individually interviewed, for a period of approximately 60 minutes using a digital recorder, and the interviews were subsequently transcribed.

IPS has undertaken a unique process for developing professional learning inquiry teams who use the TCM framework and the triples process to scaffold and support professional inquiry for learning and improved classroom practice. Participants were asked to contribute their thoughts, experiences and reflections with regard to:

- The development and transition to the use of the capability matrices;

- The experiences of the teams and support for inquirybased professional learning; 
- The co-construction of understandings of 'good' practice;

- The presence and influence of various levels of leadership and

- The nature of organisational change through this period in the use of the matrices and the triples process.

\section{TEACHER CAPABILITY MATRICES (TCMS)}

The teacher capability matrices (TCMs) were developed and negotiated by the staff over a ten-year period. They provide all of the teaching staff with a 'next steps' guide to improving their teaching practice. They present as 'living documents' because they are continually appraised and redrafted by teacher and leader teams when new professional knowledge enters the inquiry and design conversations that continually permeate across the school. As a consequence, the staff at IPS have developed various sets of teacher-created capability matrices across the curriculum as a professional development support tool to enable inquiry, self-reflection and an articulation of teacher development in reading, writing, mathematics, thinking, integration, e-learning and coaching.

When the process began ten years ago staff agreed to have outside experts come into the school to work alongside them in their classrooms as they taught. Their purpose was to explore: "...effective practice - what would it look like, what would we see teachers doing - what would we hear you saying - what would your room/environment look like?" (IPS leader).

TCMs were first developed to capture what it would look like if teachers engaged with what the outside experts were enacting. TCMs in document form highlight a gradation of capabilities identified for different curricula areas ranging from those expected of the beginning teacher to those expected of what IPS describes as the 'expert' teacher (Novice, Apprentice, Practitioner, and Expert Leader). TCMs present as an in-school teacher and leader co-constructed professional 'lens' informing what IPS call the 'triples process' (teacher observations and professional feedback for teacher inquiry into practice). The triples process began more than five years ago as a consideration of a model of 'triangulation', which was based on peer critique of various aspects of work (and occurring at a New Zealand university). Initially, IPS changed the process to also be one of performance appraisal with the two senior colleagues. "It started off with a whole set of points that they were going to assess you on" but now it is negotiated with the teacher prior to the triple process, to select the focus, unless the teacher is in their first two years of teaching $\left(\mathrm{PRT}^{1}\right)$ and then they are assessed on Reading, Writing and/or Mathematics. Feedback is modelled on a questioning process that prompts thinking on the part of the person being 'tripled'.

\footnotetext{
${ }^{1}$ Provisionally Registered Teacher
} 
The dialogue is between both of you-it's not just me speaking, I'm not just telling the person what to do...there's quite often informal dialogue occurring prior to and post triples, because people talk about it. (IPS teacher)

We noted through our interviews that triples were highly valued by the observed teachers as a 'stepping stone' to improve their teaching practice. The underpinning driver for developing and working with the TCMs is a "striving for excellence" and this is interpreted by the staff as "life-long learning and the excitement about life-long learning". The metaphor regularly used by staff is one of a "learning journey" which is "always on the move". The professional development processes focus on people thinking about the school's overarching inquiry question: "what does a good teacher do?" which drives all of their professional development processes.

The Matrices/Triples process cultivates rich conversations that go on between colleagues and there are opportunities for them - that underpins a lot of professionalism...being trusted, being allowed to work through, to grow and explore pedagogy, and to have those conversations builds professionalism. (IPS leader)

The impression provided by many staff in our interviews is that teachers grow very quickly in this environment and faster than in other places. For beginning teachers: “...they know when they come here that they're going to have to be very committed to $P D$ and really growing themselves very quickly...So, they make that decision..." (IPS leader).

The ongoing staff inquiry into refining the development of the TCMs ensures the incorporation of differing views, which helps everyone to develop shared understandings. The co-construction process creates a language and common way of describing the practice at high levels. This process encourages staff to be "initiating.... rich conversations" about their practice. Teachers inquire into their practice, locate themselves on the relevant matrix and identify goals for development to "make a shift in over the whole year". The goals are chosen by each teacher within a focus area that may be influenced by the Ministry (eg Science in 2014). "The TCMs are so diverse, sideways as well as deep, that it would be pretty hard not to be able to set a goal" (IPS teacher).

\section{THE 'TRIPLES' PROCESS}

The TCMs are enacted through what IPS describe as a 'Triples process' which engages each teacher in a process of responsibility for their own and each other's learning. It involves making sure that each teacher is constantly engaged in professional inquiry to reflect upon their work towards their goals following the triples feedback conversations and asking whether they need help to do this. The process is "actually giving feedback to people; receiving feedback, and acting on feedback (inquiry, self-reflection and trialling in practice)". Once teachers reach the Expert layer, they become a Tripler; in other 
words, they lead the observation, inquiry and feedback processes with teachers.

The term 'professional practice' is used by staff in most descriptions of the Matrices/Triples process. The time spent with an outside literacy expert encouraged the development of the 'art of questioning' in the school which demonstrates the inquiry-based logic of the practice which engages all three people in a form of learning about their practice.

There's been a few hiccups - but mostly we've developed into a 3-way learning community where me, you and the other person have all something to learn from what we saw - so it's not just 2 looking at 1 - and so we're very conscious of the fact that it's inclusive learning for the 3 of us. (IPS leader)

\section{WHAT DO THE STORIES ELICITED FROM TEACHERS AND LEADERS REVEAL ABOUT A CULTURE OF INQUIRY AT IPS?}

A particular influence on our thinking as researchers came from the teacher and leader stories of collaborative professional inquiry and development in relation to the school's highly valued professional development structures (TCMs and triples). These stories appeared to us as showing the experiences of teachers engaged in a culture of inquiry with co-constructed supports in place to guide teacher 'next steps' as professional educators embarking upon a collaborative 'learning journey'. In the next section we offer a sample of these storied recounts from the teacher and leader interviews, using a hermeneutic method to analyse the stories, and to illustrate the sophisticated nature of the IPS inquiry culture that appeared to us. For us, the stories represent an affirmation of the overarching importance of the ontological dimensions of professional inquiry bringing an epistemological learning framework to life, which we will discuss, later in the article.

\section{IPS leadership}

Rob, the principal, presented to us from the stories as an 'educational pioneer' displaying a never complacent, but rather always unsettled demeanour, an educational leader continually seeking to do better for the sake of the students. For us, he displayed a philosophical leadership practice logic that urgently sought 'to do whatever it takes' to build teacher expertise in the classroom so that the children could benefit in their learning. There was no compromise or wavering from this leadership practice logic from our reading across all of the interviews. As a consequence, his focus was always upon how best to improve teachers' professional practices in the classroom and this meant finding ways to make this happen. Rob garnered a significant professional development budget each year from the Board of Trustees at the school to make this happen and continually worked with staff to fine-tune professional development approaches.

Culture is often colloquially spoken of as "the way we do things around here" (Johnson, 1992, p.30). The culture at IPS presented to us as one of support, openness, authenticity, passion and excitement to do the best for the 
students. It also revealed itself to us as a mature culture in the sense that staff were able to have sometimes difficult professional conversations with each other without causing personal offence. Through the triples process, we noted there was an underlying philosophy of appreciative feedback that appeared to inspire professional growth, working against a culture of fear and retribution. The triples process supported a culture on inquiry centred on the teacher's focus for development and the associated questions asked by the triplers.

\section{IPS culture of inquiry}

A culture of inquiry is evident across the school. It is evident in the staffroom conversations, in the team teaching arrangements, within the practices of outside experts brought into the school to work alongside teachers in the classroom, within the declared structures and intent of the regular TCMs and triples processes. The processes work to open the inquiry 'eyes' of teachers to better see their practices and consider how best to improve them. Professional inquiry at IPS appears to be driven by a professional thirst displayed by both the teachers and leaders to strive to do better in their classroom practice. The staff continually raises questions when opportunities for professional discussion arise and these opportunities are frequent, with professional time and nuanced structures regularly provided. Always within these professional inquiry moments, whether they are individual, paired, teambased or whole school, there is a collegial awareness that support can be found within the school to help teachers and leaders seek new pedagogical understandings and approaches that can benefit their professional practices.

I don't think there ever is a...oh this isn't working, and let's put it aside. It's always...oh, if this isn't working, what are we going to do? - what actions are we going to take? how are we going to know if this is working? - how are we going to judge what the effect is? And that is prevalent even in discussions in the staff room, and among the whole staff, they will question and say well if this is what you want, how are going to know that we've achieved it how are we going to measure this to know there's been an improvement, or this effect has actually happened? (IPS leader)

They definitely gave me things to think about - because I was so focussed on what I was doing - I guess coming in from outside, they were looking at things from different angles and perspectives, so - sort of uncovered things that you hadn't even thought maybe you were doing, or that you weren't doing that could have really just changed the lesson. (IPS early career teacher)

The culture of inquiry that pervades schooling life at IPS has significant benefits upon teacher efficacy or their sense of their professional selves as teachers. Here we highlight how the school's culture of inquiry and support embodies teacher's practices and affirms deep inside 'the soul of the teacher' 
(Ball, 2003) how well they are performing and how best to attend to the always varying complexities of becoming the 'good' teacher.

\section{IPS teacher efficacy as professional 'being'}

IPS teachers know they are working in a learning community supportive of their growth as a teacher. It recognises the complexity of being a teacher (particularly an early career teacher) and offers real and valued ways to make this support happen. There was a sense of relief, a deep exhaling of being fortunate during the interviews, espoused particularly by the early career teachers. They were so 'grateful' and considered themselves 'lucky' to have arrived at a school that valued them as professionals and was authentic about supporting their growth as new teachers, showing them ways to do this. Teachers recognised that no teacher in the school was left to 'fend for themselves' in an isolated classroom, as is the common plight for beginning teachers (Johnson et al. 2016).

For me [the TCMs and triples process] just made all the difference, because suddenly I could see this is my next step, this is where I am heading. And, realistically, I was ready to throw teaching away in that first year. It was really hard and especially at such a high performing school. And once those matrices came in that gave me some guidance. And then I could talk to teachers about them as well and we could compare notes and you know, what could we do to meet this standard? And, how can I get help? And, suddenly help came from everywhere as well. (Early career teacher)

The professional 'being' of the teachers and leaders was central to the success of the culture of inquiry approach at IPS. Our hermeneutic analysis of the samples below of interview extracts, reveal to us teacher and leader 'lifeworlds' (van Manen, 1990) that are saturated within professional inquiry; of self, and of professional care and support for others (teachers and students alike), driven by an all-encompassing desire and moral imperative to do the best for students. And doing the best for students at IPS manifests in doing the professional best for each other.

Well, when you've actually set your goals, those goals are revisited. So you come back and you revisit those goals, or I might come and say; how are you getting on heading towards that goal? What can I do to help? What have you done to help yourself (part of the self-responsibility); and there'll be dialogue - it's not just OK we've done the Triples and finished - we've set these goals and now you will probably do self-reflections on how you are working towards the goals...You might have said, I need help with this. So it also makes me as the Leader accountable as well. So you are accountable for doing what you say you want to do. (IPS leader) 
So I think, being trusted - being allowed to work through to grow and explore pedagogy - and to have those conversations builds professionalism. I think the whole management excitement over continually developing ourselves and continually looking for what's the best practice and most effective in growing our learners and growing our teachers - because there's that sense of excitement all of the time - I think that's a very professional thing. (IPS leader)

Rather than being a standards-based list of professional requirements and prescriptions that must be complied with to be the 'good' teacher-'things' that are mandated from above-what we were seeing at IPS was teacher and leader infused exploratory struggles to build their own best practice standards (TCMs) that were real for their context. These carried the agreed standards into much higher expectations for being and becoming the 'good' teacher. What was evident to us was that teachers and leaders were deeply committed to not settle for managerially imposed standards, which they described to us as second best, but rather passionately committed to the educational project that was constantly presenting and evolving in their school, their place, their classrooms and across their community of learners.

\section{DISCUSSION}

The development of TCMs and the Triples process at IPS appears to be a unique and authentic expression of inquiry-based dialogue between school leaders and teachers about how teachers can seriously engage in their own learning through collaborative inquiry and be accountable for continuously improving their instructional practice. The processes also demonstrate how school leaders can acquire and enact the knowledge, skills and strength of character to hold teachers accountable for integrating what they have learned in professional development into their classroom practice. Such a model of practice is genuinely concerned for relational and humanistic educational praxis (Bills, 2011; Bills, Giles \& Rogers, 2016; Giles, et al., 2016; Rogers, 2015).

By contrast, Dall'Alba and Barnacle (2007) identify that a focus on knowledge transfer or acquisition in educational institutions treats learning as unproblematic and is neither relational nor humanistic. We understand from Freire (1970), in his discussion of the banking concept of education, that knowledge acquisition is not simply a matter of offering or pouring the 'official' or 'valued' knowledge into the receiver participant and then moving on. Similarly, for Heidegger (1998):

Merely pouring knowledge into the unprepared soul (or mind) as if it were some container held out empty and waiting. On the contrary real education lays hold of the soul itself and transforms it in its entirety by first of all leading us to the place of our essential being and accustoming us to it. (p.167) 
Here, Heidegger draws us into an awareness of the ontological (being in the world) dimensions of learning. Therefore, the notion of knowledge as foundational and absolute, which can be seen in the underpinning philosophy, design intent, and articulation of the abstract knowledge underpinning teacher, leader or school 'standards', is seriously under-theorised (Chaiklin \& Lave, 1993; Gibbons et al., 1994; Walsh, 2006) and potentially damaging.

Evidence that the National Standards are damaging schools needs to be taken seriously because it has surfaced while New Zealand's version of high-stakes assessment is still in an embryonic stage, National Standards are not going to avoid the problems found internationally; they represent a variation on the theme. (Thrupp \& White, 2013)

Contrary to the New Zealand 'standards' push for schools (Thrupp \& White, 2013) the staff at IPS demonstrated in their daily teaching practices an 'embeddedness' within an ontological inquiry paradigm which rested upon the relational and cultural character of their school community. Within this ontological positioning, an IPS school culture of inquiry flourished, manifesting with teachers embracing collaborative forms of practitioner and intellectual inquiry, skill acquisition and problem solving through the TCM and triples processes.

Good professional development practices in schools acknowledge that learning is anything but unproblematic and this in seen in the pedagogical repertoire disclosed in interview by the teachers at IPS. Unfortunately, in stark contrast to their lived embodied experiences of inquiry-based learning, the standards-based regime continues to target teachers and leaders with an emphasis on decontextualised professional practice capabilities sometimes described as performativities (Ball, 2003), which has marginalised or inadvertently misunderstood the importance of the embodiment of learning (Dall'Alba \& Sandberg, 2014). The embodiment of learning is evident in the way our body extends into, and incorporates, things in our world-an "entwinement that undermines the notion of subject and object as independent of each other... Person and world are, then, unavoidably entwined in the performance of work or everyday activities" (p. 291). Our findings, through hermeneutic phenomenological research at IPS, presents a picture about how teachers work to build learning engagement in the classroom through processes in which they seek to be involved in inquiry and reflection of their practice. Teachers declared through the interviews time and time again that they were delighted and relieved that they had every resource at their disposal to enable them to become better teachers.

A deep ontological need to do whatever it takes to improve their professional practices and to know this deeply, in a very embodied way, was evident to us. These teachers were driven by a deep ontological need to become better teachers, and in order to do this they were going through a very sophisticated inquiry for learning approach in tandem with colleagues to make the learning experience for their students' one of rigour, quality and engagement. For IPS, epistemology was in the service of ontology rather than ontology in the service of epistemology. For example, knowledge inquiry and 
transfer at IPS was attuned to ways of being; integration of knowing, acting and being in the professional learning arrangements of schooling (van Manen, 2002). This presenting phenomenon represented an attunement across the school to construct embodied subjectivity in the working lives and identities of the teaching staff.

By contrast, the 'standards' in their various guises, work to marginalise ontology. We argue, that within espoused educational 'standards', ontology is positioned in the service of epistemology (the abstract official knowledge contained within the standards), which means the standards movement fails to understand the importance of embracing how teachers and leaders live their lives, day to day, within the contextual social environs of schooling. As a consequence, they 'miss the mark' and the opportunity to engage teachers and leaders in positive and affirming transformational ways of being to build sustainable practice, teacher efficacy and quality. A narrow focus on the skills needed for teacher inquiry is therefore an inadequate approach because its very emphasis undermines skilfulness itself by its failure to integrate knowing, acting and being.

The embodiment of knowledge made possible by the presenting culture of inquiry at IPS presented in a staff commitment to openness, wonder and passion about being and becoming the 'good' teacher. This presented as integral to the professional inquiry for learning processes embraced by staff across the school. Their approach to professional learning embraced an ontological approach within and across the school's various professional development approaches. It appeared to us that the 'IPS way', a phrase frequently declared by the teachers and leaders traversing across all of our interviews, reasserted the centrality of the ontological dimensions and implications for teacher professional inquiry for learning, which within the managerialist standards regime has been subordinated by decontextualised epistemological concerns, manifesting in the current technicist New Zealand approach to professional inquiry.

\section{CONCLUSION}

Our research findings suggest that there is an overarching need to take teachers' ontological and epistemological views very seriously when schools are engaged in designing professional development opportunities. These findings contribute to areas of research that explore the impact of teachers' ontological and epistemological beliefs on teaching practice. They also provide direction for further discussion, exploration and research.

Marshalling Heidegger (1998) at this point, the problems faced by education will always be ontological and therefore systemic efforts to produce the 'good' teacher through mandated standards must be urgently reconsidered. If educational systems are serious about transformative teacher and leader change for improved student learning experiences and outcomes (which of course they declare they are), then they must become aware of the need to position the epistemology of the standards in the service of the ontology of being and becoming the 'good' teacher and 'good' leader. This is the challenge to be embraced if we are to avoid what Thrupp and White (2013) have phrased, 
creatively reworking Neil Young's infamous song, 'the national standards and the damage done'.

Manuscript Submitted: April 20, 2016

Revised Manuscript Received: August 10, 2016

Revised Manuscript Accepted: October 12, 2016 


\section{REFERENCES}

Absolum, M. (2007). Clarity in the classroom: Using formative assessment. Building learning-centred relationships, Auckland, New Zealand: Hodder Education.

Ball, S. J. (2003). The teacher's soul and the terrors of performativity. Journal of Education Policy, 18(2), 215-228.

Bills, A., Giles, D., \& Rogers, B. (2016). 'Being in' and 'feeling seen' in professional development as new teachers: The ontological layer(ing) of professional development practice. Australian Journal of Teacher Education, 41(2), 106-121. http://dx.doi.org/10.14221/ajte.2016v41n2.7

Bills, A. (2011). The (un)critical schoolteacher: Three lessons about teacher engagement work with marginalised students in neoliberal times. (Doctor of Education), University of Adelaide, Australia). Retrieved from http://hdl.handle.net/2440/72157

Black, P. and William, D. (1998). Inside the black box: Raising standards through classroom assessment. London, England: Granada Learning.

Caldwell, B. J. (2014). Realigning the governance of schools in Australia: Energising an experimentalist approach. Seminar Series Centre for Strategic Education, 233, 1-14.

Chaiklin, S., \& Lave, J. (Eds.). (1993). Understanding practice: Perspectives on activity and context (Vol. 78). Cambridge, England: Cambridge University Press.

Clarke, S., Timperley, H. and Hattie, J. (2001). Unlocking formative assessment: Practical strategies for enhancing students' learning in the primary and intermediate classroom. Auckland, New Zealand: Hodder Education.

Connell, R. (2013). The neoliberal cascade and education: An essay on the market agenda and its consequences. Critical Studies in Education, 54(2), 99-112.

Crooks, T.J. (2002). Educational assessment in New Zealand schools. Assessment in Education, 9(2), 237-253.

Dall'Alba, G., \& Barnacle, R. (2007). An ontological turn for higher education. Studies in Higher Education, 32(6), 679-691.

Dall'Alba, G., \& Sandberg, J. (2014). A phenomenological perspective on researching work and learning. In International Handbook of Research in Professional and Practice-based Learning (pp. 279-304). Rotterdam, Netherlands: Springer.

Elmore, R. F. (2002). Bridging the gap between standards and achievement: The imperative for professional development in education. Washington, DC: Albert Shanker Institute.

Freire, P. (2003). Pedagogy of the oppressed (30th Anniversary ed.), New York, NY: Continuum. 
Freire, P. (1970). The banking concept of education. In A. S. Canestrari \& B. A. Marlowe (Eds.), Educational foundations: An anthology of critical readings, (pp. 99-103). Thousand Oaks, CA: SAGE.

Gibbons, M., Limoges, C., Nowotny, H., Schwartzman, S., Scott, P., \& Trow, M. (1994). The new production of knowledge: The dynamics of science and research in contemporary societies. London, England: SAGE.

Giles, D. L. (2014). Appreciatively building higher educator's relational sensibilities. Journal of Meaning-Centered Education, 2(1). http://www.meaningcentered.org/appreciatively-building-highereducators-relational-sensibilities

Giles, D., Bell, M., Halsey, J., Palmer, C., Bills, A., \& Rogers, B. (2016). Teaching within a relational approach to educational leadership. Melbourne, Australia: Cengage Learning Australia

Harlen, W. (2007). Criteria for evaluating systems for student assessment, Studies in Educational Evaluation, 33(1), 15-28.

Hart, S., Dixon, A., Drummond, M. J., \& Mclntyre, D. (2004). Learning without limits. Maidenhead, England: Open University Press.

Heidegger, M. (1998). Plato's doctrine of truth in pathmarks. Cambridge, England: Cambridge University Press.

Johnson, G. (1992). Managing strategic change-strategy, culture and action. Long Range Planning, 25(1), 28-36.

Johnson, B., Down, B., Le Cornu, R., Peters, J., Sullivan, A., Pearce, J., \& Hunter, J. (2016). Promoting early career teacher resilience. Abingdon, England: Routledge.

Little, J. W. (1990). The persistence of privacy: Autonomy and initiative in teachers' professional relations. Teachers College Record, 91(4), 509536.

Rogers, B. (2015). Reframing professional learning within a collective profession: Rich and shared accountability as an integrated process of dialogue, observation and feedback about 'standards'. Paper presented at the AARE Conference: 29th Nov-3rd Dec 2015, Fremantle.

Ryan, M., \& Bourke, T. (2013). The teacher as reflexive professional: Making visible the excluded discourse in teacher standards. Discourse: Studies in the cultural politics of education, 34(3), 411-423.

Sachs, J. (2001). Learning to be a teacher: Teacher education and the development of professional identity. Paper presented as keynote address at the ISATT Conference. Faro, Portugal.

Shapiro, H.S. (2005). Losing heart: The moral and spiritual mis-education of America's children. Mahwah, NJ: Lawrence Erlbaum Associates.

Thrupp, M., \& White, M. (2013). Research, analysis and insight into national standards (RAINS) project: Final report: National Standards and the damage done. Hamilton, New Zealand: Wilf Malcolm Institute of Educational Research. Retrieved from 
http://www.waikato.ac.nz/ data/assets/pdf file/0010/179407/RAINSFinal-report 2013-11-22.pdf

van Manen, M. (1990). Researching lived experience. New York, NY: State University of New York Press.

van Manen, M. (1997). From meaning to method. Qualitative Health Research, 7(3), 345-369.

van Manen, M. (2002). The tone of teaching: The language of pedagogy. Ontario, Canada: Althouse Press.

Walsh, P. (2006). Narrowed horizons and the impoverishment of educational discourse: Teaching, learning and performing under the new educational bureaucracies. Journal of Education Policy, 21(1), 95-117.

Yinger, R. J., \& Hendricks-Lee, M. S. (2000). The language of standards and teacher education reform. Education Policy, 14(1), 94-106. 


\section{ABOUT THE AUTHORS}

ANDREW BILLS

Flinders University

School of Education

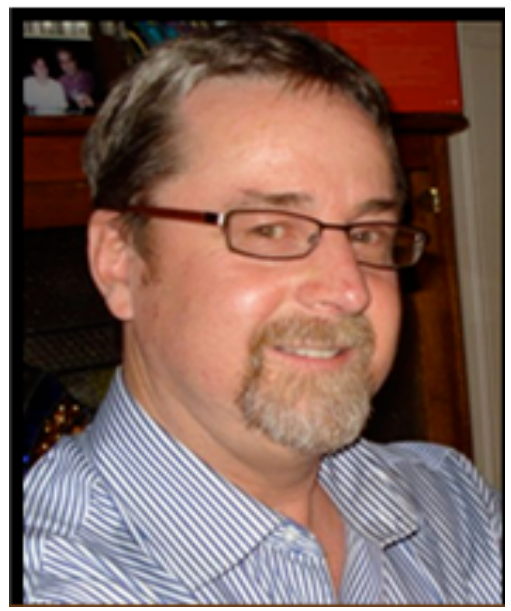

Dr Andrew Bills has a particular interest in critical sociology, action research, secondary school design and hermeneutic phenomenology as vehicles for exploring the experiential, relational \& phenomenological nature of education and educational leadership. He was formerly a special education teacher and counsellor at Mount Barker High School.

Email: Andrew.Bills@flinders.edu.au

BEV ROGERS

Flinders University

School of Education

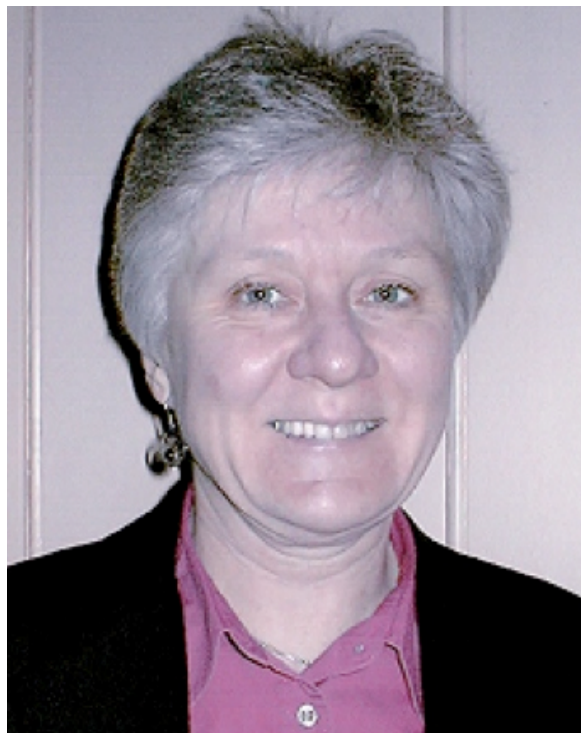

My professional background includes a long career in education, employed by the Department for Education and Child Development. Following many years as a teacher I was principal in both Whyalla and Adelaide for a total of 13 years followed by various positions in state office which included as a Director in Curriculum and consultant in HR and Workforce Development. I completed my doctorate in 2013, joining Flinders University staff in February 2014.

Email: bev.rogers@flinders.edu.au 
DAVID GILES

Flinders University

School of Education

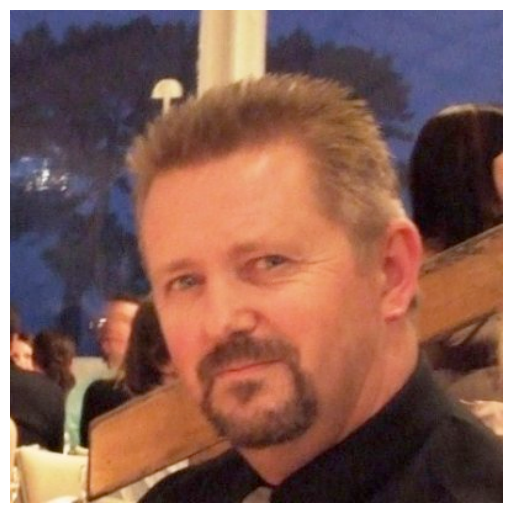

Professor David Giles has a particular interest in hermeneutic phenomenology and appreciative inquiry research methodologies as vehicles for exploring the experiential, relational \& phenomenological nature of education and educational leadership.He was formerly a primary school mathematics teacher in New Zealand.

Email: David Giles@flinders.edu.au 